\title{
On the Advantages of Applying Photoshop Software Technology in Graphic Character Design
}

\author{
Hui Zhang \\ Wuhan Textile University School of Fashion, Wuhan, Hubei, 430073
}

\begin{abstract}
Keywords: Figure image; Graphic advertisement; Digital software Photoshop; Traditional film; Traditional model
\end{abstract}

\begin{abstract}
Figure has been the main theme of art creation since ancient times, and it has been more and more widely used in graphic advertisement design nowadays. In the design of a perfect graphic advertisement character's makeup and style, every link cannot be ignored from design graphic-model selection-props preparation-makeup and styling-photography-post processing-works demonstration. The actual operation of designing graphic advertisement character is subject to the limitation of many objective factors, so appropriate application of post digital software Photoshop can make up for the deficiencies and shortcomings in designing advertisement makeup and styling so as to achieve the desired effects. In the traditional film era, due to the limitation of hardware or negligence in the production process, many places may not achieve the designer's original intention after the completion of the work. At this time, either it will be reproduced or used, which perplexed the designers. With the development of digital image processing technology, especially the emergence of digital Photoshop software, existing defects can be modified through the process of digital software Photoshop to demonstrate some special effects, etc., which shows the advantages that cannot be compared by traditional design method.
\end{abstract}

\section{Traditional Grapgic Character Modeling}

The following makeup styling work is from the 1980s, when computer software was not yet applied in the styling works, so photographic works were fixed. Due to some objective factors, photographic works would be generally used, and people could only accept some unsatisfactory places. For example, the makeup painting was not delicate enough, and the shooting effect was not ideal. The following picture especially shows that the model's eyebrow is not perfect, the face is not standard and the background is not uniform, etc.

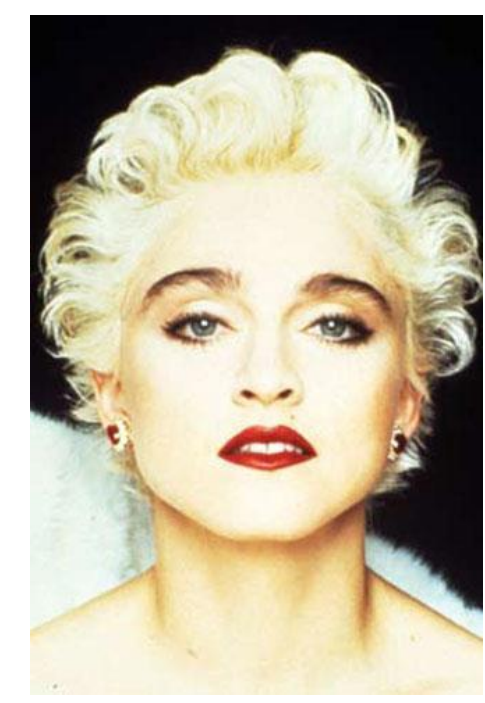

Figure 1. Modeling work in the 1980s

The following work was also a picture of a star in the 1980s. It has higher definition, but the overall brightness is not enough. However, for the obvious eye bags on the model's face cannot be 
completely covered through make-up techniques.

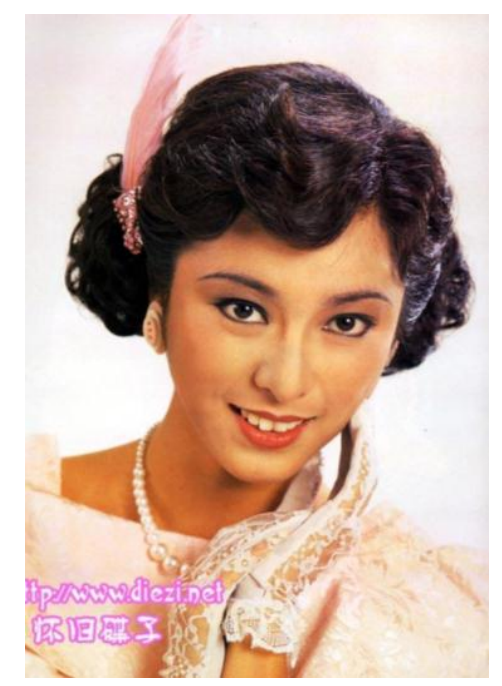

Figure 2. Modeling work in the 1980s

\section{Makeup Modeling Using Photoshop}

Before 2000, Photoshop mainly used scanning function to process images, but actually, most of Photoshop functions had nothing to do with the digital camera design popular since the late 1990s. The later version began to have image modification tools, and Photoshop was mainly good at image processing. Image processing processed the existing bitmap image and used some special effects, which can rapidly modify a damaged old photo and also beautify unsatisfactory parts on images to get satisfactory results.

Modeling Adjustment - Structure Adjustment. Asian faces are not as three-dimensional as Western faces. Facial concave and 3D structure also affect the beauty of people's faces. Makeup is to paint faces based on the face's own 3D structure, and the facial concave and convex level mainly depends on facial bones, muscles and fat layer. In order to better make the face more three-dimensional and tighten facial contour, foundations of different levels can be chosen to create the model's style. If the model's facial concave and convex structure is obvious with underdeveloped muscles, the facial structure seems to be three-dimensional. [2] When the face has a strong 3D sense, it will appear to be personal and mature, but the edges will be too clear, lacking the sense of delicate beauty. If facial structure is tender, it will appear to be gentle and sweet, but inadequate sense of three-dimension will appear to be swelling. Therefore, foundation is used to correct the facial 3D sense, which is particularly important. However, the final style is affected by the model. If the model's face is still not so three-dimensional on the picture after makeup, it then can only be adjusted by applying Photoshop software. The following picture is a comparison of effect before and after using Photoshop software.

It can be found after completing the image modeling that the model's face is not so three-dimensional, and the styling effect tends to be dull. But after being processed by the PS software, the sense of three-dimension is further enhanced, and the model's face appears to be more compact and fashionable, leaving a deep impression. 


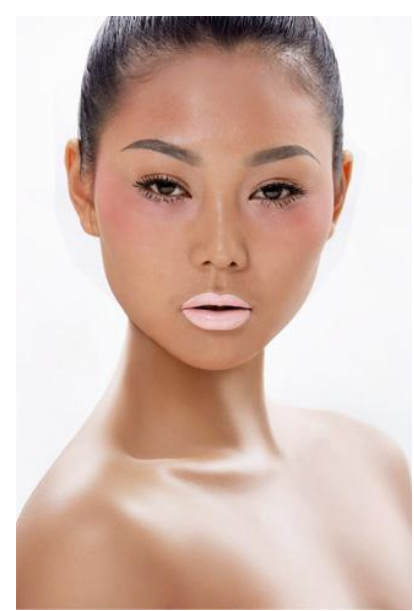

Figure 3. Before processing

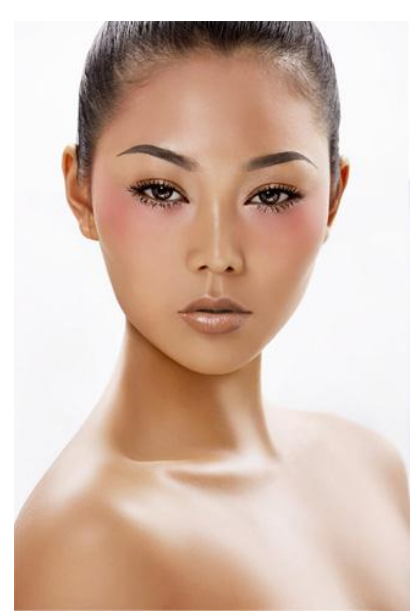

After Photoshop processing

Adjustment of Colors - Adjustment of Skin Color. Skin is the body's largest organ, and the skin has several colors: white, yellow, red, brown, and black mainly due to different race, age and different parts. The role of skin color adjustment in make-up is extremely important, and color modification determines the success of a modeling work to a large extent. If the make-up is like building high-rise, then the color modification is to lay the foundation. Like painting stress paper selection, paper selection is not good, so the effect will always be unsatisfactory. Human skin is like a mirror, its texture and color can reflect people's living environment, identity, age, physical condition, fashion elements and emotions, etc. Color modification is the main function of the improvement and modification of the appearance of the skin, because each person's skin texture, color, and most people of color are not so perfect, so through a variety of techniques to modify the healthy beautiful skin is particularly important. Color should be rosy, delicate, and shiny. Delicate skin gives unlimited aesthetic sense whether from the visual or tactile perspective. Healthy skin is beautiful skin. Healthy skin should be shiny ruddy, soft and delicate, elastic, moderate tension, highly dynamic, neither rough nor greasy, both shiny, and less wrinkles.

The following is a student's works. Due to the insufficient lighting and simple photographic equipment, the shooting effect is not so satisfactory, and the picture is too dark, not clear. Objective factors do not allow reproduction, so at this time, only post-processing can be used to achieve the designer's desired effects. Thus, later on, we use Photoshop software to modify and adjust the picture so achieve the final desired effects.

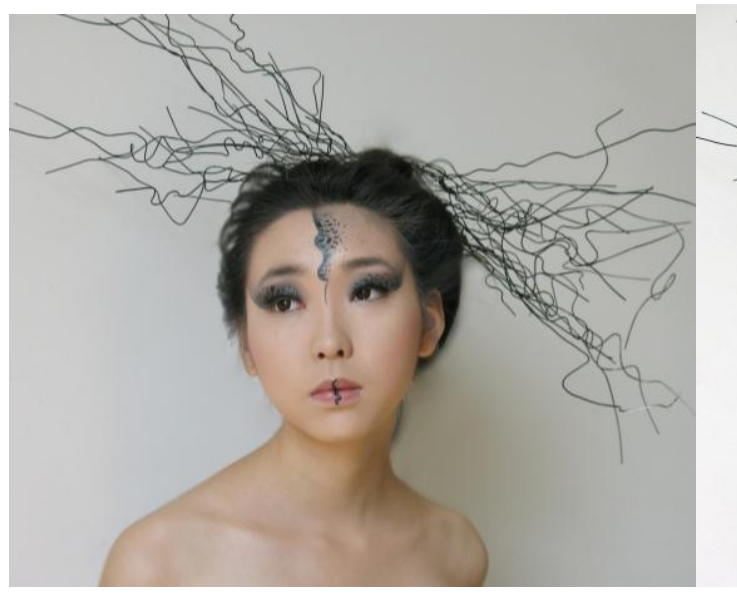

Figure 4. The original picture

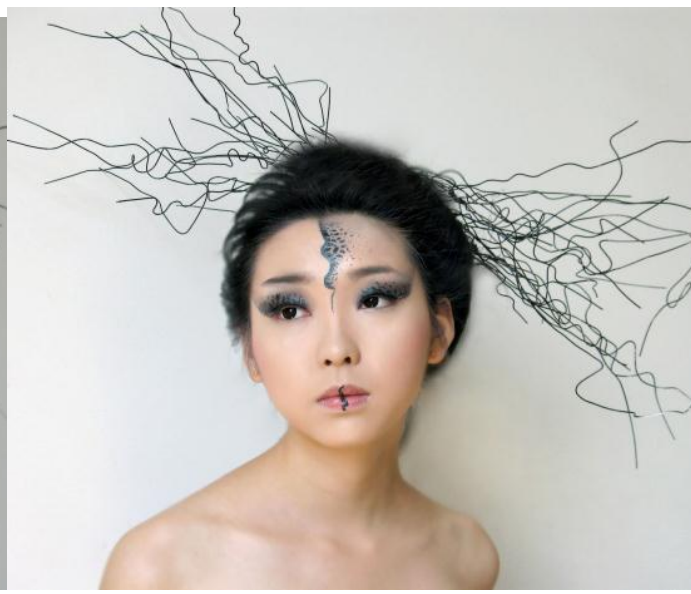

After Photoshop processing

Adjustment of Texture - Adjustment of Skin Texture. Everybody is afraid of acne, spots and other blemishes on the skin, because they would destroy our ideal smooth and delicate skin. In the following picture, due to the serious pimples on the model's face, and even after the skin is 
modified with foundation, the pimples still exist that more powder can only make the skin look uncomfortable and like a mask. At this time, we can use Photoshop software for later adjustment to make the skin look delicate and shiny like a baby's skin.

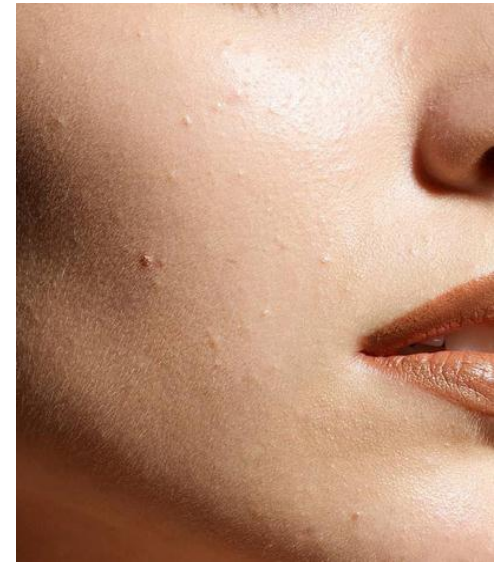

Figure 5. Before processing

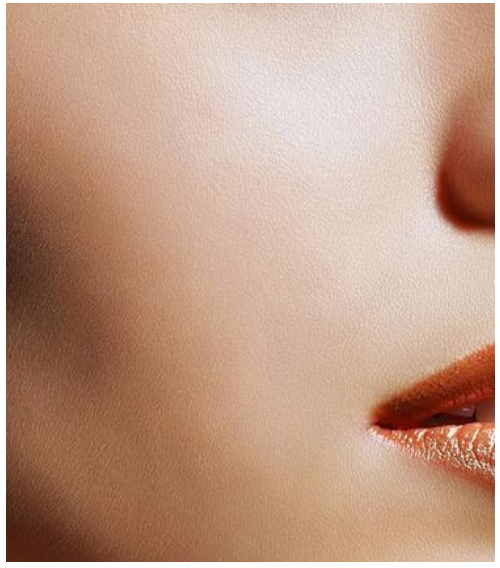

After Photoshop processing

The following style is a commonly seen work in most of today's fashion magazines with complete style and prominent visual effects. Such styling works are adjusted and modified with the Photoshop software later to demonstrate the final different effect.
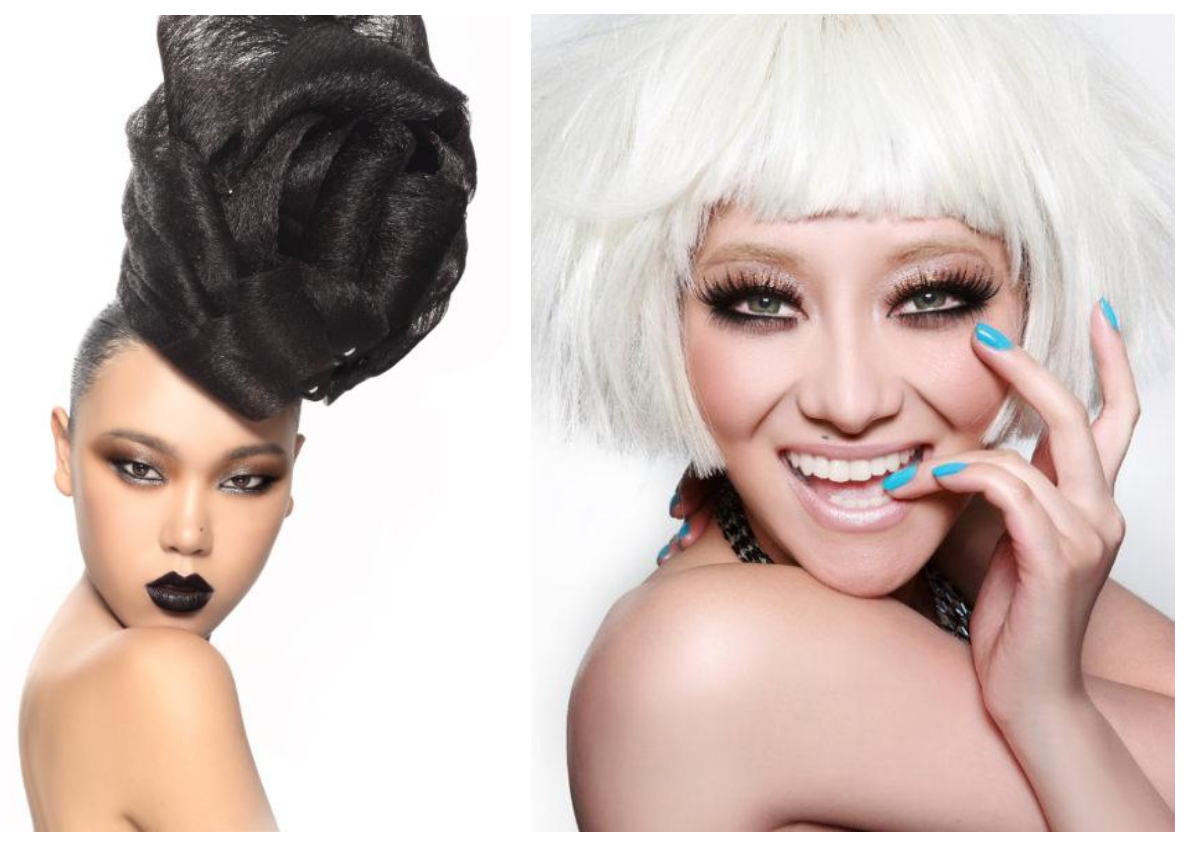

Figure 6. Come from Tony Studio website

\section{Conclusion}

From the above modeling work analysis, the traditional makeup modeling completes the effect and uses the software Photoshop later production the effect to carry on the contrast, the single traditional technology application has not been able to satisfy the designer the demand. Today, with the help of computer software Photoshop, not only can make up the makeup process Hardware deficiencies, you can also repair the make-up process problems.

The application of Photoshop in graphic advertisement design makes me deeply feel that digital technology plays an irreplaceable role in art creation. The application of digital technology makes graphic advertisement figure design stand on a higher level. Even with insufficient hardware, 
magnificent works can also be created at low cost, which not only saves resources and reduces cost, but also improve the efficiency. At present, we cannot completely deny traditional figure style, which is natural and authentic, showing simple beauty. Today's style should learn from it. Although digital technology cannot replace traditional arts, it brings great impact to traditional arts.

\section{References}

[1] Fat Bird Studio. Photoshop CS5 complete self-study manual [M] Beijing hope electronics press, July 2003.

[2] Jiahua Xu. Foundation of Makeup [M]. China Textile Press, October 2009.

[3] Mao Geping. Mao Geping Makeup Art [M].Hangzhou: Zhejiang People's Publishing House, 1999:100-150.

[4] Liwa Huang, Yuan Gao, Min Chen. On Experimental Teaching of Makeup [J]. Changchun Medical, 2006, (02).

[5] Donald. A. Noman, Design Psychology, Translated by Qiong Mei, China Citic Press, 2003.

[6] Jiaxun He. Case of Modern Advertisement - Theory and Analysis [M]. Shanghai: Fudan University Press, 1998.

[7] Shouzhi Wang. World Graphic Design History [M].Beijing: China Youth Press, 2002.

[8] Jinhai Zhang. Analysis of Classic Advertising Cases in the World [M]. Wuhan: Wuhan University Press, 2000.

[9] (Japan) Kenya Hara. Design in Design [M]. Shangdong: Shangdong People's Publishing House, 2006.55-57.

[10](America) Newark, What is Graphic Design? [M], China Youth Publishing House, January 2006. 